\title{
Bulut Muhasebe ve İşletmelerde Uygulanması
}

\author{
Ayşe Nur BUYRUK AKBABA*
}

\section{$\ddot{O Z Z E T}$}

Bulut muhasebe, bulut bilişim tabanl muhasebe sistemlerini kullanan işletmelerin hizmet sağlayıcılardan hesaplama, depolama ve bağlantı kaynakların ihtiyaçları kadar satın alıp, kendilerinin yönetebileceği ortam üzerinde kullanabilecek hizmetlere sahip olabilmeleridir. Kurulan sanal yapı ile işletmelerin yatırım, yenileme, alt yapı sağlama ve yönetim gibi faaliyetlerin yapılması sağlanmaktadır. Bulut bilişim, uygulamaların internet ortamında bulunan bir uzak sunucu üzerinden çalıştırlması ya da kullanıctya ait verilerin uzak sunucu üzerinde her an erişilebilir şekilde bulundurulmasını sağlayan bir servis yapısıdır. Bulut bilişsimin hizmet modelleri ve kullanış biçimleri vardır. Bulut muhasebenin uygulanmasında işletmelere yararı olabileceği gibi riski de vardır. Çalışmada, bulut muhasebe kavramına, işletmeler için avantaj ve dezavantajlarına, tercih edilme yoğunluğuna değinilerek bu sistemin işletmeler için daha anlaşılır olmasının sağlanması amaçlanmıştır. Bu amaçla konuya ilişskin bilgiler kavramsal olarak ele alınmış, literatür incelenerek teori ile uygulamada yapılması gereken muhasebe işlemleri hakkında bilgilere yer verilmiş, bulut biliş̧im ve bulut muhasebenin iş̧letmelerde uygulanma oranı hakkında bilgiler aktarılmış ve muhasebeleştirilmesinde esas alınabilecek görüşler hakkinda öneriler sunulmuştur.

Anahtar Kelimeler: Muhasebe, Bulut Muhasebe, Bulut Bilişim.

JEL Sinıflandırması: M40, M41.

\section{Cloud Accounting and Application in Business}

\section{ABSTRACT}

Cloud accounting is the ability of businesses using cloud computing based accounting systems to purchase computing, storage and connectivity resources from service providers as much as they need and to use services on the environment they can manage. With the established virtual structure are provided activities such as investment, renewal, infrastructure provision and management. Cloud Computing is a service structure that enables applications to be run over a remote server located on the internet or to make the user's data accessible on the remote server at any time. Cloud computing has service models and usage patterns. In the implementation of cloud accounting, there are risks as well as benefits to businesses. In the study is aimed to make the system more understandable for the enterprises by referring to the concept of cloud accounting, the advantages and disadvantages for enterprises and the intensity of preference. For this purpose, information about the subject has been conceptually reviewed and the literature has been examined and some information about the accounting procedures that should be done in practice are given information about the rate of application of cloud computing and cloud accounting in business enterprises, and suggestions about the views that can be taken as basis for the accounting are presented.

Keywords: Accounting, Cloud Accounting, Cloud Computing.

Jel Classification: M40, M41.

Makale Gönderim Tarihi: 13.08.2018

Makale Kabul Tarihi: 03.10.2018

\footnotetext{
* Dr., Bitlis Eren Üniversitesi, İktisadi ve İdari Bilimler Fakültesi, abuyruk@beu.edu.tr, ORCID ID: 0000-0003-4940-7138.
} 


\section{GíRiş}

Bulut muhasebe, endüstri 4.0 ile ilgili bulut bilişim, teknoloji kavramları arasında yer almaktadır. Endüstri 4.0 dördüncü sanayi devrimi olarak bilinmektedir. Tüm dünyada yaşanan teknolojik gelişmeler sonucunda her alanda olduğu gibi muhasebe alanında da bazı ihtiyaçlar ortaya çıkmış ve bu ihtiyaçların karşılanması adına işletmelerin teknolojik gelişmelere uyum sağlaması gereklilik haline gelmiştir.

Bulut bilişim, uygulamaların internet ortamında bulunan bir uzak sunucu üzerinden çalıştırılması, kullanıcıya ait verilerin uzak sunucu üzerinde her an erişilebilir şekilde bulundurulmasını sağlayan bir servis yapısıdır. Bulut bilişim; donanım, bant genişliği, hafıza kapasitesi ve performans konusunda hizmet kalitesini sunar ve kullanıcılar için şeffaftır.

Bulut muhasebede, gerçek zamanlı muhasebe entegrasyonu ile muhasebe işlemlerinde kolaylığın sağlanması hedeflenmektedir. Türkiye'de, bulut muhasebenin uygulanabilmesi için işletmelerde kullanılan muhasebe yazılımları ve muhasebe meslek mensuplarına yönelik web tabanlı uygulama vardır. Çalışmada, işletmelerdeki muhasebe uygulamalarının teknolojik gelişmelere işletmelerin muhasebe uygulamaları açısından uyum sağlayabilmesi için konuya ilişkin bilgilerin aktarılması ve önerilerin sunulması amaçlanmıştır.

Bu amaç ile çalışmanın ilk iki bölümünde, bulut muhasebe ve bulut bilişim ile ilgili bazı kavramlara, üçüncü bölümde muhasebe alanında uygulanmasına, dördüncü bölümde muhasebeleştirilmesine yönelik Tekdüzen Hesap Planı ve muhasebe standartları açısından açıklamalara, son bölüm olan beşinci bölümde ise yapılan araştırmaya göre ulaşılan sonuca yer verilmiştir. Ayrıca çalışmanın üçüncü bölümünde, bulut muhasebenin işletmelere faydası ve risklerinin neler olduğuna, işletmeler tarafından uygulanma oranı ele alınmıştır. Uygulanma oranına göre işletmeler için güçlü ve zayıf yönleri belirlenerek çözüm önerilerine değinilmiştir. Çalışmada, konuya ilişkin bilgiler kavramsal olarak ele alınmış, mevcut çalışmalar incelenerek teori ile uygulama da yapılması gereken muhasebe ile ilgili işlemlerin neler olduğuna ilişkin bilgiler sunulmaya çalışılmıştır.

\section{BULUT BİLISŞIM İLE İLGILİ BAZI KAVRAMLAR}

$\mathrm{Bu}$ bölümde, endüstri 4.0 kavramına, endüstri 4.0 teknoloji araçlarına, bulut bilişim kavramına, bulut bilişim hizmet modelleri ve kullanım biçimleri ile bulut bilişim özelliklerine ilişkin bilgilere yer verilmiştir.

\subsection{Endüstri 4.0 Kavramı}

Endüstri 4.0 kavramı gelecekte rekabetçi ortamda ayakta kalmak için önemli bir stratejidir. Buna, rekabetçi ürünlerin ve hizmetlerin tasarımı ve uygulanmasının yanı sıra esnek lojistik ve üretim sistemleri de dahildir. Endüstri işletmeleri günümüzde ürünlerin bireyselleştirilmesinin artması, kaynak verimliliğinin artırılması ve pazara girme süresinin kısaltılması gibi zorlukların üstesinden gelmek için endüstri 4.0 kavramı üzerinde durmaktadırlar (Yıldız A., 2018:548).

Sanayi devrimi (Industrial Revolution), insan ve hayvan gücüne dayalı üretim tarzından, makine gücünün hakim olduğu üretim tarzına geçiştir. Bu tarz üretim 18. Yüzyılda 
İngiltere'de, özellikle dokuma sektöründe ortaya çıkmış, daha sonra diğer alanlara yayılmıştır. Makineye dayalı üretime geçişle birlikte üretimin şekli ve miktarı da artmıştır (Küçükkalay, 1994:52).

Tarihte ilk devrim tarımda gerçekleşmiştir. İnsanların yerleşik hayata geçerek tarım toplumunun oluşması insanoğlunun gerçekleştirdiği ilk sosyal devrimdir. Bu süreci sanayi devrimi izlemektedir. Sanayi devrimi ise üç büyük değişim olarak ortaya çıkmıştır. 17501890 yıllarında başlayan ve Birinci Sanayi Devrimi, olarak isimlendirilen sürecin bir diğer adı da Buhar Çağıdır. Buhar çağı ile anılmasının nedeni ise James Watt'ın buluşu olan buhar makinesi dönemin başlangıcı olarak kabul edilmesidir. Bu dönemde dokuma sanayi gelişmiş ve metalürjide değişimler gerçekleşmiştir. Gemicilik ve demiryolları çelik üretiminin artışı ile gelişen sanayiler olmuştur.

İkinci Sanayi Devrimi ise 1870 yılı itibari ile başlayan ve doğu bloğunun çöküşü olan 1989 yılına kadar devam eden süreçtir. Bu dönemde petrolün endüstri ve ulaşımdaki etkinliği keşfedilerek kullanılmaya başlanmıştır. Küreselleşmenin de etkinliği bu dönemde artmış ulaşımdaki ilerlemeler hızlı gelişim göstermiştir.

Elektriğin kullanımı Üçüncü Sanayi devriminin başlangıcı olarak gösterilmektedir. Üretimin elektrik ile yapıldığı bu döneme ek olarak, hem mekanik hem elektronik alanların gelişmesi, dijital teknoloji ile birlikte programlanabilen cihazlar ve bilişim teknolojilerinin ortaya çıkması izlemiştir. Bilgisayar teknolojisinin ilerlemesi ve internetin de hızla gelişmesi bu dönemin informatik devrim olarak da bilinmesini sağlamıştır.

Sanayi devrimindeki değişimler, mekanik ve mikro elektronik alanındaki gelişimler bilgi toplumunun oluşmasına neden olmuştur. Enformasyon devrimi ile birlikte işletmeler ve kurumlar yeniden yapılanma sürecine girmiştir. Küreselleşme sürecinin hız kazanması ile birlikte tüm dünyada teknolojiye uyumlu bir dönüşüm yaşanmış ve bilgi toplumunun oluşumu sağlanmıştır. Bilgi toplumunun bugün gelmiş olduğu son yeni sanayi devrimi Endüstri 4.0 olarak ortaya çıkmıştır. Siber-Fiziksel sistemlerin üretimde devreye girmesi ile kişiye özel, doğayla barışık, görsel algısı yüksek olan bir üretim sürecinde iyileştirme gerçekleştirilebilecektir (Bulut ve Akçac1, 2017:52). Endüstri 4.0, endüstri işletmelerinde makinelerin, fabrikaların siber-fiziksel sistemler ile gelecekte küresel bağlantılar inşa etmektir (Gilchrist, 2016:195).

Endüstri 4.0, dördüncü sanayi devrimi olarak tanımlanmaktadır. İşletmelerin, güncel otomasyon, veri değişikliği, tamamen yaşanan teknoloji esaslı değişimdir (Y1lmaz, 2018:289). Endüstri 4.0, geliştirilmiş teknoloji, güvenlik, robot, bulut sistem gibi araçlar ile gelecekte verimlilik ve başarı için tanımlanmıştır (Bartodziej, 2016:29). Endüstri 4.0 ile ürünlerin pazara hızlı sunumu; insan, makine ve sistemlerin birbiri ile bağlanarak fabrikaların verimliliğinin artması beklenmektedir. Türkiye'nin de otuz yıl içinde bu süreci tamamlayacağ 1 öngörülmektedir. Endüstri 4.0 kavramı ortaya çıkmadan önce Siemens gibi bazı şirketlerin üretiminde dijitalleşme uygulamaları başlamıştı 1996 yılında tamamen entegre otomasyon adını verdikleri yöntem ile işletmeler süreçlerinin bileşenlerini koordine edebilmiş ve yazılım ile donanımlarını bu süreçlere entegre etmiştir (Ejder Erturan ve Ergin, 2017:16). 
Endüstri 4.0, makine gücünün; insan gücünün yerini alarak üretim süreçlerini kendiliğinden yönetebilir hale gelmesi olarak tanımlanabilir. Makinelerin bilgisayarlar ve internet teknolojilerindeki yeni gelişmeler sayesinde koordine edilebilir hale gelmesi yeni sanayi devrimini ortaya çıkarmıştır. "Nesnelerin İnterneti" kavramı olarak bilinen bu yeni sistem sayesinde üretimde ileri seviyeye atlanmış ve fabrikaların kendini yönetebilir olması ile ileri düzey teknolojiye geçiş sağlanmaktadır (Bulut ve Akçacı, 2017:53).

Endüstri 4.0, "zeki fabrika" olarak da adlandırılabilecek türde yapılar oluşturmak üzere imalat teknolojileri içerisinde özellikle otomasyon ve veri değişimi alanlarında, siberfiziksel yapıları, nesnelerin interneti kavramını ve bulut bilişim sistemlerini günümüz şartlarına uygun duruma getirmiştir. Oluşturulan bu tür fabrikalar, kullandığı siber-fiziksel süreçler ya da oluşturdukları çok yönlü düşünme mantığı ve fiziksel dünyanın bir kopyası sayılabilecek türde bilgi yığınlarıyla değerlendirilmektedirler (Özkurt, 2016:14).

Endüstri 4.0'1 başarılı bir biçimde uygulamaya geçirerek, üretim platformlarını dönüştürmenin; küresel rekabet gücünün artması, küresel değer zincirinden alınan yüksek katma değerli ürünler payının artması ve işgücü profilinin gelişmesi gibi üç temel faydasının olması mümkündür (TÜSİAD, 2016:41).

\subsection{Endüstri 4.0 Teknoloji Araçları}

Endüstri 4.0 teknoloji araçları, teknoloji tabanlı uygulanan kavramlardır. 3 boyutlu yazıcıları (3D), IoT nesnelerin interneti, akıllı fabrikalar, grafik ortamında artırılmış gerçeklik, yapay zeka, siber-fiziksel sistemler, siber güvenlik, büyük veri, otonom robotlar, simülasyon, sistem entegrasyonu, sıfıra yakın marjinal maliyet ve bulut bilişim sistemi gibi kavramları Endüstri 4.0 ile ilgili yeni teknoloji araçlarına örnek olarak verebiliriz (Bulut ve Akçacı, 2017:54-59).

3D yazıcılar sayesinde dijital ortamdaki modeller somut nesneler halinde üretilebilmektedir. Teknik olarak 3D yazıcılar, dijital ortamdaki bilgisayar destekli tasarım dosyalarından (Computer Aided Design) karmaşık nesneleri üretebilmektedir. 3D yazıcılar üretecekleri fiziksel nesneleri ince katmanlar halinde katmansal olarak üretebilmektedir (Kuzu Demir vd., 2016:484).

Fiziksel dünya ile siber dünya arasındaki iletişim ve koordinasyonu içeren yapıların bütünü Siber Fiziksel Sistemler (CPS) olarak adlandırılmaktadır. CPS'nin başlica rolü, üretimin çevik ve dinamik gereksinimlerini yerine getirmek ve tüm sanayinin etkinliğini ve verimliliğini arttırmaktır (Yıldız A., 2018:549).

Nesnelerin birbiri ile iletişimini olanaklı kılan yapılara Nesnelerin İnterneti (IoT) adı verilmektedir. Nesnelerin interneti ile çok sayıda ekonomik firsatların ortaya çıkması beklenmekte ve umut verici teknolojilerden biri olarak kabul edilmektedir (Yıldı A., 2018:550).

Robotlar, Endüstri 4.0'da üretimde en aktif rolü üstlenmesi beklenen araçlardandır. Robotlara daha esnek görevlerin yüklenmesi düşünüldüğü için, robotlar her geçen gün daha otonom ve daha işbirlikçi olmalıdırlar. 
Simülasyonlar, Endüstri 4.0 ile operasyonel faaliyetlerin değişmez bir parçası olmaları beklenmektedir. Simülasyonlar, üretimde fiziksel dünyayı sanal ortamlarda sunmaktadır. Simülasyonlar sayesinde, makine ayarları ile kurulumları, üretim araç ve gereçlerinin yerleşimleri, sanal olarak test ve optimize edilebilmektedir (Sayar ve Yüksel, 2018:90).

Bulut tabanlı imalat (CBM), Endüstri 4.0'ın başarısına önemli katkı sağlayacak bir diğer yükselen kavramdır. CBM, müşteri tarafindan oluşturulan değişken talebe yanıt vermek için verimliliği artıran, ürün ömrü maliyetlerini düşüren ve optimum kaynak tahsisine izin veren, geçici, yeniden yapılandırılabilir siber-fiziksel üretim hatları oluşturmak için paylaşılan çeşitlendirilmiş ve dağıtılan üretim kaynaklarının bir paylaşım kümesine talep üzerine erişimden yararlanan bir ağa bağlı üretim modeli olarak tanımlanmaktadır (Yıldız A., 2018:550).

Siber Güvenlik (Cybersecurity); endüstri 4.0 ile gelen bağlantı ve iletişim protokolleri ile birlikte artacak siber tehditlere karşı kritik sistemlerin ve üretim hatlarının güvenliğinin kurulması çok önemlidir. Güvenlik sağlanırken makinelerin ve kullanıcıların; erişim yönetimleri, gelişmiş kimlik güvenlikleri, haberleşme sistemleri esas alınmaktadır (Sayar ve Yüksel, 2018:91).

Endüstri 4.0'da nesnelerin birbirleri ile haberleștiği önemli yerlerden biri de "akıllı" teknolojilerle donatılmış ve hiçbir insanın çalışmaması nedeni ile karanlık fabrikalar olarak da adlandırılan "akıllı fabrikalardır". Çin'de gerçekleştirilen ve cep telefonu modülü üreten ilk karanlık fabrikada robotların kullanılması örnek olarak verilebilir (Yı1dız A., 2018:551).

Artırılmış Gerçeklik (Augmented Reality); operatörler, sanal ortamda siber butonu tıklayarak makineleri ile etkileşime girebilmekte ve parametrelerini değiştirebilmektedirler. Artırılmış gerçeklik ile operasyonel veriler ve bakım talimatlarını almak mümkün olmaktadır. $\mathrm{Bu}$ avantajlardan dolayı; şirketler karar verme ve iş prosedürlerinin geliştirmek için artırılmış gerçekliği kullanacaklardır (Sayar ve Yüksel, 2018:92).

\subsection{Bulut Bilișim, Hizmet Modelleri ve Kullanım Biçimleri}

Bulut bilişim, uygulamaların internet ortamında bulunan bir uzak sunucu üzerinden çalıştırılması ya da kullanıcıya ait verilerin uzak sunucu üzerinde her an erişilebilir şekilde bulundurulmasını sağlayan bir servis yapısı olarak tanımlanmaktadır. Web ara yüzü bilgiyi her yerde ve herkes için ulaşılabilir hale getirirken; bilgi işlem gücünü her yerde ve herkes için kullanılabilir hale getirmiştir (Henkoğlu ve Külcü, 2013:64).

Bulut bilişimde her kullanıcı bu sisteme ulaşabileceği bir aygıtla sisteme ulaşmakta ve sistemin sunduğu hizmetlerden istediği ölçekte yararlanmaktadır. (Çetin vd., 2013:2). Bulut bilişim; belirli uygulamalar, platform ve altyapı ile kullanıcılarına kullandıkları teknoloji araçlarına göre bazı hizmetler sunulması şeklinde çalışma esasına sahiptir. Bulut bilişimin çalışmasına ilişkin döngü aşağıda yer alan şekilde belirtildiği gibidir: 


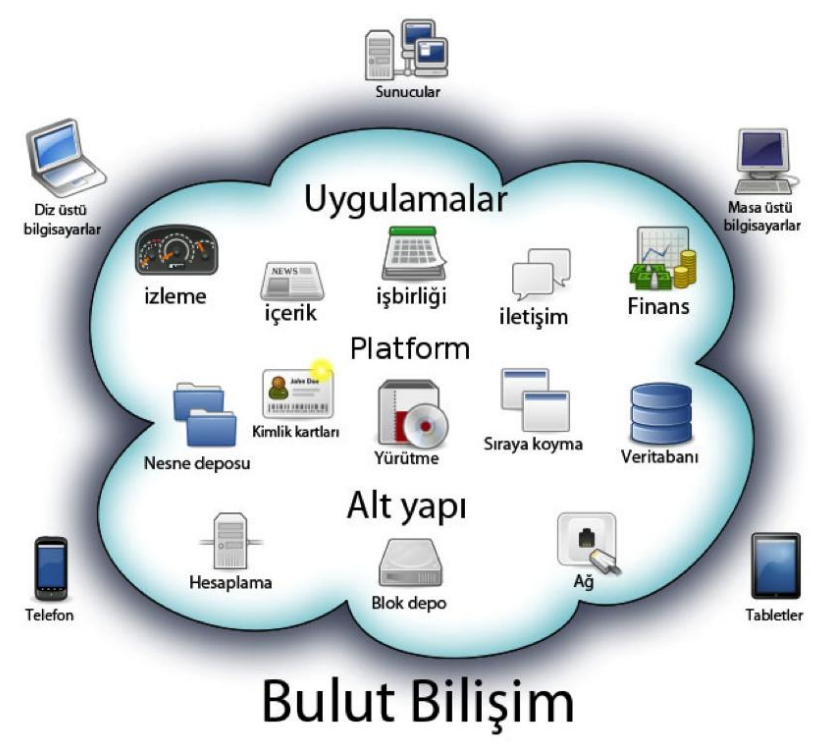

Şekil 1. Bulut Bilişim Çalışma Şeması

Kaynak: Çetin vd., 2013:2.

Bulut bilişim kullanıcılarına bazı hizmetleri sunmaktadır. $\mathrm{Bu}$ hizmetler; yazılım hizmeti, platform hizmeti ve altyapı hizmeti olmak üzere üç tür hizmet modelinden oluşmaktadır (Elitaş ve Özdemir, 2014:98). Yazılım hizmeti, kullanıcıların uygulamalara erişmek için kendi sistemlerine herhangi bir kurulum yapmadan internete bağlı herhangi bir ortamdan bulut bilişim üzerindeki uygulamalara erişerek çalışma yapabilmeleridir. Uygulamalara, web tarayıcıları gibi ara yüzler (Web tabanlı e-posta gibi) aracıllğı ile çeşitli kullanıcı cihazlarından erişilebilmektedir. Platform hizmeti, servis sağlayııı, müşteriye kendi uygulamasını geliştirip, çalıştırabileceği bir platform sunmasıdır. Altyapı hizmeti, altyapının bir bulut servisi olarak sunulması modelinde müşseri ihtiyacı olan işlemci, depolama, ağ kaynağı ve diğer temel bilişim kaynaklarını kendisi yapılandırması, bunların üzerine ihtiyacı olan işletim sistemi ve uygulamaları kurabilmesidir (Yüksel, 2012:12).

Kullanım biçimine göre; genel bulut, özel bulut, melez bulut ve topluluk bulutu olmak üzere sınıflandırılmaktadır. Genel Bulut (Public Cloud): Bulut bilişim hizmeti sunan üęüncü bir tarafa ait olmakla birlikte, internet üzerinden genel kullanıma açık bulunan hizmetlerdir (Yıldız Ö. R., 2009:8-9). Genel bulut, internet üzerinden web ara yüzü aracilığıyla genel kullanıma sunulan hizmetlerdir. (Google Apps, Amazon, Windows Azure gibi) (Henkoğlu ve Külcü, 2013:65).

Özel Bulut (Private Cloud): Bir organizasyon, işletme ya da tekil bir kişi için olan bulut bilişim biçimidir (Ruparelia, 2016:31). Bulut hizmet sağlayıcı, kurumun kendisi olabileceği gibi, üçüncü bir bulut hizmet sağlayıcı da olabilir. Kurum dışından tüm erişim yolları kapatılarak sadece kurum içi hizmet verilir (Henkoğlu ve Külcü, 2013:65).

Melez Bulut (Hybrid Cloud): Bir bulut bilişimde iki ya da daha fazla genel, özel ya da topluluk bulutu içermesidir (Jamsa, 2012:6). Bir kurumun verileri özel bulut içinde yer alırken, bazı servisleri genel bulut üzerinden halkın kullanımına açılabilmektedir. Melez bulut 
henüz yaygın olarak kullanılan bir kullanım biçimi değildir. Örnek olarak IBM, Juniper verebiliriz (Henkoğlu ve Külcü, 2013:65).

Hibrit ya da karma bulut; çok sayıda genel ve özel bulut modellerinin bütünleştirilmesi ile oluşur. Karma bulut, hem genel bulut hem de özel buluta uygulamaların nasıl dağıtılacağının belirlenmesi açısından karmaşıktır (Turan, 2014:304).

Topluluk Bulutu (Community Cloud): Belirli bir topluluk ya da gruba sunulan bulut hizmetidir. Topluluğu oluşturan unsurlar, ortak çalışma alanında bulunan kurumlar da olabilmektedir (Henkoğlu ve Külcü, 2013:65).

\subsection{Bulut Bilişim Özellikleri}

Bulut bilişim özellikleri şu şekildedir:

1) Her şey tarayıcı ile sağlanmaktadır. Hiçbir masaüstü uygulamasına veya ekstra tarayıcı eklentisine gerek yoktur (Yüksel, 2012:5).

2) Kaynakların veri merkezleri üzerinde ölçeklenebilirliği ve istendiği zaman ve istendiği kadar elde edilebilmektedir.

3) Web hizmetleri ve İnternet servisleri gibi iyi kurulmuş ara yüzlerine erişilebilirliği ve yerden bağımsız (programlama dili, işletim sistemi, platform, fiziksel mekan vs.) olması açısından kullanıcı odaklı ara yüze sahiptir.

4) Bulut bilişimin donanım, bant genişliğgi, hafiza kapasitesi ve performans konusunda hizmet kalitesi güvencesi verir.

5) Bulut bilişim sistemleri kullanıcılar için şeffaf bir şekilde müstakildir. Bulut kullanıcısının isteği doğrultusunda buluttaki yazılım ve veriler otomatik bir şekilde basit bir ortamda yeniden yapılandırılıp birleștirilebilir.

6) Bulut bilişim, yatırımdan fazlasını ve sermaye harcaması istemediği gibi kullanıcıların sunulan hizmet ve kapasite için ihtiyaç duydukları kadar ödeyebilmesi imkanına sahiptir (Turan, 2014:305).

\section{BULUT MUHASEBE VE ISSLETMELERDE UYGULANMASI}

Bulut muhasebe ve geleneksel muhasebe yazılımları karşılaştırıldığında bazı farklılıklar vardır. Geleneksel yazılımlarda işletme lisans sahibi olmak gibi hakka sahip iken bulut muhasebe yazılımlarında ise kiralama hakkına sahiptir. Donanım, Windows\&SQL Server, bakım maliyetleri geleneksel yazılımda şirket tarafından karşılanırken bulut muhasebe yazılımda ise kendi bünyesi içindedir. Kullanıcı sayısı geleneksel yazılımda lisansla sınırlı, bulut yazılımda ise sinırsizdır (Aytekin vd. 2016:55).

Endüstri 4.0'ın muhasebe uygulamalarında bulut bilişim de belirleyici olmaktadır. Bulut muhasebe sayesinde verilerin sisteme otomatik girişi ve uzaktan erişimi sağlanabilmekte, mevzuattaki değişimler izlenebilmekte ve beyannameler otomatik doldurulabilmektedir. 
Endüstri 4.0 sürecinde muhasebe ve muhasebe meslek mensuplarının geleceğ $i$ konusunda bazı radikal görüşler de bulunmaktadır. Buna göre muhasebeciler gelecekte bürolarda bulunmayarak, muhasebe meslek mensupları sanal bürolar ile işlerini yürütebilecektir. Bilişim teknolojisinin büyük gelişimi ile internet ortamında birinin bilgisayarı açması ve çevrimiçi olması yeterlidir. Bu yeni muhasebe bürosu modeli yalnızca çalışanlar için değil, aynı zamanda işverenler için de maliyetlerin düşürülmesi noktasında çok avantaj sağlamaktadır. Bu tür değişiklikler finansal analistleri, yatırım denetçilerini, kredi denetçilerini, mali denetleyicileri, profesyonel yatırımcıları, tüccarları, uluslararası finansal raporlama/muhasebe standartları uzmanlarını ve finansal danışmanları etkileyecektir (Yürekli ve Şahiner, 2017:158).

Ensütri 4.0 ile yaşanması beklenen, hatta bir takım yazılım programları ile kısmen de olsa gerçekleştirilebilen uygulama, muhasebe işlemlerinin gerçek zamanlı olmasıdır. Gerçek zamanlı muhasebe entegrasyonu sayesinde tüm işlemler gerçek zamanlı ve e-defter usulüne uygun olarak kaydedilmekte, muhasebe fişindeyken tek bir tuşla kaynak fişe gidilebilmekte ve tekrar entegre olmadan muhasebe fişlerinin güncellemesi sağlanabilmektedir (Can ve Kiymaz, 2016:111).

Endüstri 4.0 ve muhasebe üzerine çalı̧malar halen istenilen seviyede yaygınlaşmamıştır. Bu konuda Endüstri 4.0 ve çevre muhasebesine etkileri konusundaki yapılan çalışmalarda Endüstri 4.0'ın dijital altyapısı sayesinde çevre muhasebesinin geliştirilebileceği üzerinde durulmuştur. Özellikle Endüstri 4.0'ın ilgili sektörlerde, şirket boyutlarında, farklı yönetim rolleri ve işbirliği ortamlarında, tedarikte olduğu gibi, daha doğru, yüksek kaliteli, gerçek zamanlı çevre yönetimi muhasebesini ve çevre raporlamasını kolaylaştıracağı belirtilmiştir (Yürekli ve Şahiner, 2017:159).

Bulut muhasebe ile muhasebe verilerinin sisteme otomatik yüklenmesi ve uzaktan girilmesi, "Machine to Machine (M2M) communication" ile makinelerarası iletişimin sağlanması, radyo frekansı ile satın alınan bütün ürünlerin tutarının ayrı ayrı okutularak tespit edilmesi yerine tek seferde hesaplama kolaylığının olması, elektronik etiket ile her gün gerçekleştirilen fiyat belirleme, etiket kesme, kontrol işlemlerinin bilgisayara yerleştirilen düzenek ile tek tuşla ürünlerin fiyatlarının raflara dijital olarak iletilmesi, elektronik barkod uygulaması ile kayıp ve çalıntıların engellenmesi, anlık hareket işlemleri ile stok sayımının gün sonunda değil de işlemin gerçekleştiği anda yapılması yaygınlaşması beklenen endüstri 4.0 uygulamaları arasındadır (Can ve Kıymaz, 2016:113-115).

Bulut bilişim işletmelere bazı teknik faydalar sağlamaktadır. Sağladığı bu teknik faydalar aşağıda belirtildiği gibidir:

$>\quad$ Donanım ve yazılım maliyetini azaltır.

> Uzaktan erişim kolaylığı sağlar.

$>$ Depolama kapasite sınırlamalarının ortadan kaldırır (Henkoğlu ve Külcü, 2013:66-67).

Bulut muhasebe, bulut teknoloji için gerekli yazılımların düzenli olarak güncellenmesini sağlar (Kelly vd., 2016:294). 
Adaptasyon-Bulut bilişim teknolojisi kullanılarak hazırlanan bir yazılımın kurulumu geleneksel yazılım kurulumundan çok daha kolaydır.

Uyum-Bulut aracılığıyla muhasebe programlarını çalıştırmak muhasebe ve iç kontrol standartları dahil olmak üzere farklı donanımlar ile de uyumludur.

Erişim Kolaylığı - Personel, tedarikçiler ve müşteriler ofislerine gitmeye gerek kalmadan, bilgilerini herhangi bir yerden erişerek güncelleyebilirler.

Deneme süresi söz konusudur. Bulut içinde mevcut çok çeşitli uygulamalar ve hizmetler vasıtasıyla muhasebe yazılımları için deneme imkanı sunarlar.

Kişiselleştirme-Bulut üzerinde faaliyet gösteren işlemler, sistemi temelden itibaren yeniden tasarlamaya gerek duyulmaksızın, değiştirilebilir yapılandırmalar sayesinde, şirket ya da kişilerin ihtiyaçlarına uygun hale getirilebilmektedir.

Paylaşım ve İşbirliği - Bulut bilişim, kullanıcıların işbirliğini artıracak ve bilgi paylaşımını sağlayacak yönde yazılım ve servisler geliştirmelerine olanak tanır.

Ölçeklenebilirlik ve Ayarlanabilir Kapasite - Bulut, kullanıcıların tüketimlerini kendi ihtiyaçları doğrultusunda şekillendirmelerine imkan veren, sürekli aktif bir hesaplama ve depolama kaynağıdır.

yap1labilir.

Esneklik ve Verimlilik - Talebe göre kapasite artırımı ve azaltımı hızlıca

Sabit Yatırım Maliyetinin Olmamas1-Kullanıldığı kadar ödeme ve ne ödeneceği belirlidir.

Çevre Dostu-Yerel sunucu kullanımına göre \%30 daha az enerji kullanımı ve karbon salınımı sağlar. Bu oran küçük işletmeler için daha da fazladır (Aytekin vd., 2016:5657).

Bulut bilişim ile işletmelerin yaşadığı bazı sorunlar vardır. Yaşanan bu sorunlar aşağıda belirtildiği gibidir:

$>\quad$ Bulut bilişim, kullanıcı firmanın verilerini hizmet sağlayıcı firmaya emanet ettiği için hizmet sağlayıcı firmanın sistemi içerisinde tutulan bu verilerin gizliliğini sağlaması gereklidir. Verilerin gizliliğinin sağlanması, sadece yetkili kişilerin veya uygulamaların bu verilere erişebilmesi demektir. Ancak bulut bilişimde ilgili taraf, uygulama ve cihaz sayısı arttığından bu gizliliğin sağlanması zorlaşmakta ve gizlilikle ilgili riskler artmaktadır (Seyrek, 2011:707).

Uygulamaların yavaş çalışması ve düşük hızlarda servis sorunlarına neden olur.

Uzaktan erişim ve güvenlik sorunları yaşanır.

Verilerin nerede olduğunu bilmeme sorunu oluşur. 
$>\quad$ Hizmet alınan firmaların güvenilirliği, yeterliliği ve denetlenmesi sorunları yaşanır (Henkoğlu ve Külcü, 2013:67-69).

Kötü internet bağlantısı - bulut içindeki verilere doğrudan erişim için mutlaka internet bağlantısı gerekir. İşletmelere faaliyetlerini yönetebilmek ve verilerini yedekleyebilmek için güçlü ve hızı bir internet bağlantısı gerekmektedir. satıcıya bağımlı olunur.

Kontrolün kaybedilmesi (bakım, güncelleme ve uygulamanın yönetimi) sonucu

Bağımlılık - İşletmenin bulut üzerinde yeni bir uygulama kullanması durumunda önceki program üzerindeki veriler kullanılamaz hale gelebilir ve bulut üzerindeki uygulamaya bağımlı kalabilir.

Hizmet devamlılığ 1 ve kullanılabilirliği-bulut bilişim hizmet sağlayıcılarda hizmet kesintisine sebebiyet verebilecek bir sorun yaşanması durumunda, bu hizmet sağlayıcıdan hizmet tedariki yoluna gitmiş tüm şirketler birden bundan etkilenecek ve kesinti sonuçlanana kadar, şirketlerin müşterilerine hizmet veremez hale gelmelerine sebep olacaktır.

$>\quad$ Hizmet sağlayıcı bağımlılı̆̆ı ve veri kilitlenmesi-depolanan veri ve kullanılan uygulamalar dolayısıyla bağımlı olunması, uygulanan fiyat politikalarına karşı esnek olamamaya, hizmet sağlayıcısının mimarisinde var olabilecek açıklık ve zayıflıklar sonucu oluşabilecek arıza ve saldırılardan dolayı veri kaybına uğramaya sebebiyet verebilir.

$>\quad$ Yönetim ara yüzü ve uzaktan erişim-bulut bilişim hizmet sağlayıcıların kullanıcılarının hizmetlerini yönettikleri ara yüzler, internet üzerinden erişilebilir olmaları ve geniş yönetim imkanları nedeni ile internet tarayıcıların ve uzaktan erişimin zayıflıkları düşünüldüğünde, yüksek güvenlik riski taşımaktadırlar.

$>$ Bant genişliği ve veri transferi-kullanıcıların veri işleme ve saklama faaliyetlerinden arındırılıp, verilerin uygulamaların giderek daha yoğun veri kullanmaya başlamasıyla, verilerin kullanıcıdan bulut bilişim hizmet sağlayıcısına taşınmasında zorluklar yaşanması (Aytekin vd., 2016:58).

Bazı ülkelerde bazı verilerin ülke sınırları dışına çıkarılması yasak olduğundan yasal engeller de olumsuz yönü arasındadır (Seyrek, 2011:708).

Klasik ve bulut bilişim tabanlı muhasebe programları arasında bazı farklılıklar vardır. Bu farklılıklar, aşağıdaki tabloda olduğu gibidir: 
Tablo 1. Klasik ve Bulut Bilişim Tabanlı Muhasebe Programlarının Karşılaştırılması

\begin{tabular}{|c|c|}
\hline Klasik Muhasebe Programları & Bulut Tabanlı Muhasebe Programları \\
\hline Veriler elle girilir. & Veriler otomatik girilir. \\
\hline Sisteme uzaktan erişim bulunmamaktadır. & Sisteme uzaktan erişim bulunmaktadır. \\
\hline Kurulum ve güncelleme elle gerçekleştirilir. & $\begin{array}{l}\text { Kurulum ve güncelleme uzaktan erişim ile } \\
\text { gerçekleștirilir. }\end{array}$ \\
\hline İş yer & İ ş yeri dışında bağımsız çalışma imkanı vardır. \\
\hline Yedekleme yerel terminalde gerçekleşir. & $\begin{array}{l}\text { Yedekleme bulut bilişim sist } \\
\text { terminalde gerçekleşir. }\end{array}$ \\
\hline takip edilir. & $\begin{array}{l}\text { değişiklikleri bulut bilişim sisteminden } \\
\text { r. }\end{array}$ \\
\hline Bey & meler otomatik doldurulur ve gönderilir. \\
\hline İșlemlerde zaman kayıpları yaşanır. & İşlemlerde zaman kayıpları yaşanmaz. \\
\hline $\begin{array}{l}\text { Faturalar ve diğer resmi belgeler elle doldurulur ve } \\
\text { gönderilir. }\end{array}$ & $\begin{array}{l}\text { Faturalar ve diğer resmi belgeler web tabanlı } \\
\text { doldurulur ve gönderilir. }\end{array}$ \\
\hline $\begin{array}{l}\text { İşletme yöneticilerinin finansal verilere istedikleri an } \\
\text { uzaktan erişimi mümkün değildir. }\end{array}$ & $\begin{array}{l}\text { İşletme yöneticilerinin finansal verilere istedikleri } \\
\text { an uzaktan erişimi mümkündür. }\end{array}$ \\
\hline $\begin{array}{l}\text { Mali müşavirler ile müşteri işletme } \\
\text { iletişim yoktur. }\end{array}$ & $\begin{array}{l}\text { Mali müşavirler ile müşteri işletmeler } \\
\text { sürekli web tabanlı bir iletişim vardır. }\end{array}$ \\
\hline
\end{tabular}

Kaynak: Aytekin, Alper vd., (2016). Yeni Bir İş Modeli: Muhasebe Alanında Bulut Bilişim, Uluslararası Yönetim İktisat ve İşletme Dergisi, ICAFR 16 Özel Sayısı, s.55.

Bulut bilişim tabanlı muhasebe sistemlerini kullanan işletmeler, hizmet sağlayıcılardan hesaplama, depolama ve bağlantı kaynaklarını ihtiyaçları kadar satın alıp, kendilerinin yönetebileceği ortam üzerinde kullanabilecek hizmetlere sahiptir. Kurulan sanal yapı ile işletmelerin ilk yatırım, yenileme, alt yapı sağlama ve yönetim gibi maliyetlerden tasarruf etmesi sağlanmaktadır. Sanallaştırmada işletmelerin artan hizmet talepleri çok daha esnek ve hızlı karşılanabilmektedir (Elitaş ve Özdemir, 2014:104).

Yapılan çalışmalarda; bulut teknolojinin muhasebe bilgi sistemine olumlu etkisi olduğu, işletme yönetiminin satın alma maliyetini azalttığı belirtilmektedir. Bulut muhasebe uygulamasının işletmelerin ekonomik kazançlarını arttıracağı açıktır (Sugahara vd., 2017:136). Bulut teknoloji ile bilgisayarda bilginin depolandığı online veriler sağlanır. Bankalar için online işlem yapılması, sosyal medya erişim ya da bir gmail hesabına sahip olmak, muhtemel bulut teknolojisinin kullanıldığ göstergesidir. Bulut muhasebe, online muhasebe işlemlerinin yapıldığ 1 sistemidir (Kelly vd., 2016:293).

Türkiye'de bulut bilişim kullanan muhasebe yazılımlarına örnek olarak; LOGO Tiger Enterprise, Tiger Plus, Go Plus, Mikrofortuna ve LUCA verebiliriz. ETA ve VEGA'nın ise teknolojik yeniliklere uyum sağlayamamıştır, bulut çözümleri bulunmamaktadır (Aytekin vd., 2016:58-59). Bulut muhasebenin bazı riskleri olmasına karşın muhasebe büroları, denetim çalışmalarında bulut teknolojinin her bir özelliğinden faydalanabilirler (Becker ve Drum, 2012:58).

Bulut bilişim tabanlı muhasebe sistemlerinin yaygın olarak kullanılan çalışma yapısı Şekil 2'de tanımlanmıştır. Web tabanlı çalışan sistemde "Mali Müşaviri", "Şirket Yetkilisi" ve "Gezici Kullanıcı" olmak üzere üç tip kullanıcı bulunmaktadır. Her kullanıcı sisteme internet bağlantısı olan sabit veya gezici herhangi bir cihazla zaman ve mekan k1sitlaması olmadan şifreleri ile bağlanabilmekte ve işlem yapabilmektedir. İşletmelere ait tüm muhasebe verileri hizmet sağlayıcıya ait sunucularda saklanmaktadır. Kullanıcılar verilerini istedikleri zaman 
yedekleme imkânına da sahiptir. Verilerin güvenliğine ait sorumluluk hizmet sağlayıcıya ait olup; hizmet sağlayıc1, işletmelerin finansal verilerinin kötü niyetli üçüncü şahısların eline geçmesini önlemek amacıyla, gerekli güvenlik önlemlerini de almak zorundadır.

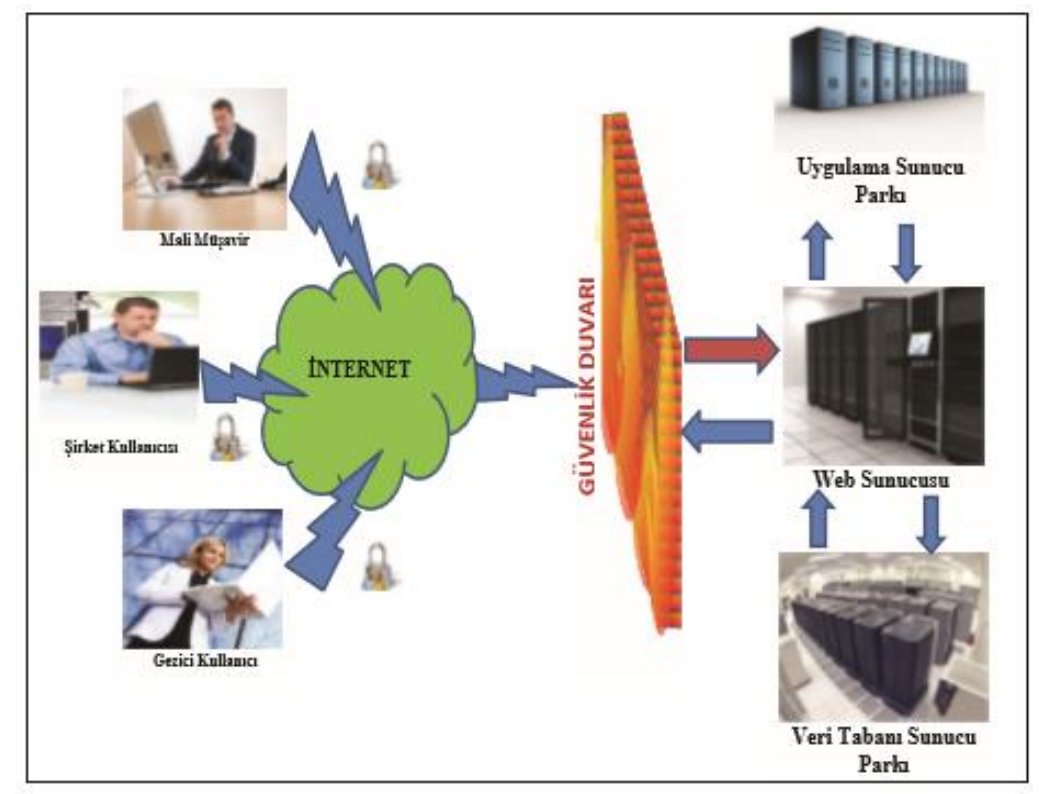

Şekil 2. Yaygın Olarak Kullanılan Bulut Bilişim Tabanlı Muhasebe Kaynak: Elitaş ve Özdemir, 2014:105.

Yukarıda tanımlanan muhasebe sisteminde hizmet sağlayıcı bulut bilişimin "Özel Bulut” yapısını kullanmaktadır. Bu yapının kullanılmasının en önemli sebebi güvenlik kaygısıdır. Sunucularında işletmelerin önemli finansal verilerini saklayan hizmet sağlayıcılar, bu yöntemle verilerin kötü niyetli kişilerin eline geçmesini engellemeyi amaçlamaktadır.

Bulut bilişimin en önemli özelliği esnek ve geliştirilebilir yapıda olmasıdır. Örneğin, bulut bilişim tabanlı muhasebe sistemlerinin hizmet sağlayıcıları, yine bulut bilişim yapısını kullanan bankalarla yaptıkları anlaşmalarla, banka hareketlerinin otomatik olarak muhasebeleștirilmesi imkanını kullanıcılarına sağlamaktadır. Bu durum otomatik muhasebe kayıtları için atılmış önemli bir adımdır. Ayrıca "Özel Bulut" yapısına sahip muhasebe sistemleri bu sayede "Melez Bulut" yapısına da kavuşmuş olmaktadır (Elitaş ve Özdemir, 2014:105-106).

Türkiye'de bulut bilişim çerçevesinde özel bir düzenleme bulunmamakla birlikte bankacılık sektöründe, bilgi sistemleri kapsamında uygulamada olan "Bankalarda Bilgi Sistemleri Yönetiminde Esas Alınacak İlkelere ilişkin Tebliğ" ve destek hizmet firmaları ile bankaların ilişkilerini düzenleyen "Bankaların Destek Hizmetleri Alımına İlişkin Yönetmelik" mevcuttur. İlgili tebliğ ve yönetmelik ile bankacilık sektöründe mevcut olan finansal verilerin, altyapının ve operasyonların güvenliği, bütünlüğü ve erişilebilirliği temin edilmektedir (Cantürk, 2013:51). İşletmelerde kullanılan muhasebe yazılımlarında yaşanan güncel gelişmelere göre yazılımları güncellemiş olmaları da gelişimin boyutunu göstermektedir.

Türkiye'de internet ve internet teknolojilerinin kullanımının dünya ortalamalarında olduğu görülmektedir. Forrester Araştırma Şirketi'nin verilerine göre, ülkemizdeki 
işletmelerin \% 31'i buluta geçmiş durumdadır ve \% 40'1 ise buluta geçmeyi düşündügünü belirtmektedir. En fazla üretim şirketlerinin başta geldiği görülürken kamu sektörünün de yüzde 25'inin bulut bilişimi kullandığı görülmektedir (Öz, 2016: 74).

Bulut bilişimin muhasebe alanında kullanımı konusunda dikkate değer bir unsur kullanıcılara sunulan yazılımların çeşitliliğidir. Şu anda farklı boyuttaki işletmelere yönelik hazırlanmış olmakla birlikte yerli yazılımların; LUCA, t360, Patrofin, Dia, 1TÇ, Reeleezee, LOGO Bulut, MEP, vb. 10'dan fazla olduğu görülmektedir. Bunun yanında yurtdışı kaynaklı yazılımlar; SAP, ZoHo da az olmakla birlikte bir seçenek olarak bulunmaktadır.

2005 y1lında kullanıma sunulan LUCA Projesi, Türkiye Serbest Muhasebeci Mali Müşavirler ve Yeminli Mali Müşavirler Odaları Birliği (TÜRMOB) ile Temel Eğitim ve Staj Merkezi (TESMER) tarafindan geliştirilen Türkiye'nin ilk internet tabanlı merkezi muhasebe sistemidir. Bulut mimari teknolojisinin yazılım servis (SaaS) olarak sunulması modelinin Türkiye'deki ilk başarılı uygulaması olan LUCA sistemi web tabanlı merkezi sistem olması nedeniyle iş süreçlerini başarı ile yönetmeyi sağlamış, teknoloji sayesinde önemli boyutta avantajlar sunmuştur. Sistemin kullanımı ile sağlanacak etkinlik ve verimlilik işletmelerin iş süreçlerine önemli katkıda bulunmaktadır (Öz, 2016: 74).

Bulut muhasebe ile meslek mensubu kısa sürede ve daha çok müşteriye hizmet verebilmekte, ek lisans bedeli ödemeden müssteri ya da kullanıcı sisteme eklenebilmekte, birden fazla yedekleme kopyalama olduğu için gelecekte ortaya çıkabilecek riskleri en aza indirgemekte yedekleme maliyetlerinin ortaya çıkmasını engellemektedir. Mevzuatın güncel olduğu modüller sunulmakta, kamu kuruluşlarına gönderilmesi gereken e-beyanname, ebildirge gibi yasal belgelerin sistem üzerinden doldurularak kolay bir şekilde gönderilmesi sağlanmaktadır. Bulut muhasebe ile Türkiye Finansal Raporlama Standartlarına uygun bir altyapının oluşturulması herhangi bir sıkıntı yaşanmadan raporların düzenlenmesi sağlanmaktadır. Esnek yapıya sahip olması nedeniyle kullanıcıların ihtiyacına yönelik eklemelerin yapılması kolaydır. Güvenlik kaygısı nedeni ile özel bulut şeklinde kullanılan bulut tabanlı muhasebe sistemlerinin bankalar ve kamu kurumlarına ait bulut sistemlerine entegre edilmesi ile karma (hibrit) bulut yapısı ortaya çıkmaktadır (Öz, 2016:75-76).

İşletmelerin internet kullanım, web sayfasına sahip olmaları, internet bağlantısında genişbant internet kullanımı, bilişim teknolojilerin kullanılması bulut bilişim ve muhasebe için önemlidir. Bu kullanımlara yönelik araştırmalar yapılmıştır. 2017'de yapılan; ücretli bulut bilişim uygulamalarını kullanan girişimler ve girişimlerde bilişim teknolojileri kullanımı araştırmalarına ilişkin bilgiler aşağıdaki 2 ve 3 nolu tablolarda yer almaktadır.

Tablo 2. Ücretli Bulut Bilişim Uygulamalarını Kullanan Girişimler (\%)

\begin{tabular}{|l|l|l|l|l|}
\hline \multirow{2}{*}{ Çalışan Sayısı } & \multicolumn{2}{|c|}{ Türkiye } & \multicolumn{2}{c|}{ AB } \\
\cline { 2 - 5 } & \multicolumn{1}{|c|}{$\mathbf{2 0 1 4}$} & \multicolumn{2}{c|}{$\mathbf{2 0 1 6}$} & \multicolumn{2}{c|}{$\mathbf{2 0 1 6}$} \\
\hline $10+$ & 6.8 & 10.3 & 19.0 & 21.0 \\
\hline $10-49$ & 5.8 & 9.1 & 17.0 & 19.0 \\
\hline $50-249$ & 10.6 & 14.4 & 24.0 & 29.0 \\
\hline $250+$ & 13.6 & 20.3 & 35.0 & 45.0 \\
\hline
\end{tabular}

Kaynak: Türkiye İstatistik Kurumu (TÜİK), 2017, Sayı 15. 
Tablo 3. Girişimlerde Bilişim Teknolojileri Kullanımı Araştırması

Çalışan sayısına göre büyüklük grubu

\begin{tabular}{|c|c|c|c|c|c|c|c|c|}
\hline \multirow[b]{3}{*}{ Ekonomik faaliyet } & \multirow{2}{*}{\multicolumn{2}{|c|}{$10+$}} & \multirow{2}{*}{\multicolumn{2}{|c|}{$10-49$}} & \multirow{2}{*}{\multicolumn{2}{|c|}{$50-249$}} & & \\
\hline & & & & & & & \multicolumn{2}{|c|}{$250+$} \\
\hline & 2016 & 2017 & 2016 & 2017 & 2016 & 2017 & 2016 & 2017 \\
\hline Genel & 93,7 & 95,9 & 92,8 & 95,4 & 96,9 & 97,8 & 99,5 & 99,7 \\
\hline İmalat sanayi & 94,6 & 96,1 & 93,7 & 95,3 & 96,9 & 98,5 & 99,5 & 99,8 \\
\hline $\begin{array}{l}\text { Elektrik, gaz, buhar ve havalandırma sistemi } \\
\text { üretim ve dağıtımı ile su temini; } \\
\text { kanalizasyon, atık yönetimi ve iyileştirme } \\
\text { faaliyetleri }\end{array}$ & 97,4 & 98,3 & 97,8 & 98,6 & 94,6 & 96,9 & 100,0 & 100,0 \\
\hline İnşaat & 90,2 & 93,2 & 88,4 & 92,3 & 97,7 & 97,0 & 99,3 & 100,0 \\
\hline $\begin{array}{l}\text { Toptan ve perakende ticaret; motorlu kara } \\
\text { taşitlarının ve motosikletlerin onarımı }\end{array}$ & 95,7 & 97,7 & 95,3 & 97,4 & 97,9 & 100,0 & 100,0 & 99,9 \\
\hline Ulaştırma ve depolama & 91,3 & 95,3 & 90,5 & 96,1 & 95,4 & 88,2 & 100,0 & 99,6 \\
\hline Konaklama ve yiyecek hizmeti faaliyetleri & 89,0 & 92,8 & 87,1 & 92,1 & 98,3 & 96,2 & 99,7 & 100,0 \\
\hline Bilgi ve iletişim & 99,5 & 99,8 & 99,5 & 99,8 & 99,7 & 100,0 & 100,0 & 100,0 \\
\hline Gayrimenkul faal & 96,9 & 96,9 & 97,8 & 96,4 & 91,3 & 100,0 & 100,0 & 100,0 \\
\hline Mesleki, bilimsel ve teknik faaliyetler & 97,9 & 99,9 & 97,7 & 100,0 & 98,9 & 98,9 & 100,0 & 100,0 \\
\hline İdari ve destek hizmet faaliyetleri & 93,3 & 94,8 & 92,8 & 92,3 & 92,3 & 98,0 & 98,8 & 98,8 \\
\hline $\begin{array}{l}\text { Bilgisayarların ve iletişim araç ve } \\
\text { gereçlerinin onarımı }\end{array}$ & 100,0 & 100,0 & 100,0 & 100,0 & 100,0 & 100,0 & 100,0 & \\
\hline
\end{tabular}

Kaynak: Türkiye İstatistik Kurumu (TÜíK), Girişimlerde Bilişim Teknolojileri Kullanımı Araştırması, 2017.

Yapılan araştırma sonuçlarına göre Tablo 3 'te görüldüğü gibi 10 ve daha fazla çalışanı olan girişimlerin internete erişim oran1 2016 yılında \%93.7 iken 2017 yılında \%95,9 olmuştur. Çalışan sayısı büyüklük gruplarına göre internet erişim oranları ise 2017 yılında; 10-49 çalışanı olan girişimlerde \%95,4 iken, 50-249 çalışanı olan girişimlerde \%97,8, 250 ve üzeri çalışanı olan girişimlerde ise \%99,7'dir. Bilgisayar kullanım oranı 10 ve daha fazla çalışanı olan girişimler için 2016 yılında 95,9 iken 2017 yılında \%97,2 olmuştur.

Faaliyet alanlarına göre araştırma sonuçlarını incelediğimizde; imalat sanayinde en yüksek oranın $\% 99,5-\% 99,8$ ile 250 ve üzeri çalışana sahip işletmelerde olduğu, bu faaliyet alanında yıllar itibari ile artış olduğu görülmektedir. Elektrik, gaz, buhar ve havalandırma sistemi üretim ve dağıtımı ile su temini; kanalizasyon, atık yönetimi ve iyileştirme faaliyetlerinde; çalışan sayılarına göre oranın genel olarak yüksek olduğu, 250 ve üzeri işletmelerde oranın \%100 olduğu tespit edilmiştir. İnşaat alanında; en yüksek oran \%99,3 ile 2016 yılında 250 ve üzeri çalışana sahip işletmelerde, 2017 yılında oranın \%100 olduğu, en düşük oranın 2016 yılında \%88,4 ile çalışan sayısı 10-49 olan işletmelerde görülmüştür. Toptan ve perakende ticaret; motorlu kara taşıtlarının ve motosikletlerin onarımı, ulaştırma ve depolama, konaklama ve yiyecek hizmeti faaliyetleri, bilgi ve iletişim, gayrimenkul faaliyetleri, mesleki, bilimsel ve teknik faaliyetler, idari ve destek hizmet gibi faaliyetleri gösteren işletmelerde ise faydalanma oranının tamamı 50-249 ile 250 ve üzeri olan işletmelerde olmuştur. Benzer sonuçlar söz konusu olduğu için bu faaliyet alanına sahip işletmeler için sonuç birlikte değerlendirilmiştir. Bilgisayarların ve iletişim araç ve gereçlerinin onarımını yapan işletmelerde faydalanma oranı yüzde yüz olarak tespit edilmiştir. 
Yapılmış olan bu araştırmanın sonucunu özetleyecek olursak; çalışan sayısı fazla olan işletmelerde faydalanma oranın da daha yüksek olduğunu ve genel olarak incelendiğinde faydalanma oranının \%87'nin altında olmadı̆̆ını söyleyebiliriz.

TÜİK tarafından yapılan diğer araştırmalarda bulut bilişimle bağlantılı aşağıdaki

Veriler elde edilmektedir.

İşletmelerin \% 72,9'u 2017 yılında web sayfasına sahip iken, bu oran bir önceki yı1 \%66 olarak hesaplanmıştır. Web sayfası sahiplik oranı en yüksek oran çalışan sayısı 250 ve üzeri işletmelerdedir.

İşletmelerin \%94,2'si 2017 yılında internete erişimde genişbant bağlantı kullanmıştır. Genişbant İnternet erişimine sahip girişimlerin abone oldukları İnternet bağlantı hızları dikkate alındığında, \%22,5'i $10 \mathrm{Mbit} / \mathrm{s}$ altında, \%59'u 10-99 Mbit/s hız aralığında ve \%18,5'i ise $100 \mathrm{Mbit} / \mathrm{s}$ ve üzeri hızda internet kullandığı belirlenmiştir (TÜİK, 2017).

Bilişim teknolojileri kullanım araştırması sonuçlarına göre, 2017 yılında 10 ve daha fazla çalışanı olan girişimler \%45,7'si sosyal medya uygulamalarını kullanmıştır. Sosyal medya kullanımı çalışan sayısı büyüklük grubuna göre incelendiğinde en yüksek oran 250 ve üzeri çalışanı olan işletmelerde olduğu görülmektedir. İşletmelerin sosyal medya kullanımı ekonomik faaliyet sınıflamasına göre incelendiğinde ise bilgi ve iletişim sektöründe yer alan girişimlerin \%80'i sosyal medyayı kullanırken, bu sektörü \%72,8 ile bilgisayarların ve iletişim araç ve gereçlerinin onarımı grubu ve $\% 57,3$ ile konaklama ve yiyecek hizmeti faaliyetleri takip etmiştir.

Avrupa Birliği İstatistik Ofisi 2016 yılı verilerine göre girişimlerin sosyal medya uygulamalarını kullanım oranı \%71 ile en yüksek Malta'da olduğu gözlemlenmiştir. Bu oran; Avrupa Birliğine üye 28 ülke (AB-28) ortalaması için \%45 iken Türkiye'de \%38 olmuştur (TÜIKK, 2017, Sayı:67).

AB-28 için araştırma yapılmıştır. Yapılmış olan araştırmaya göre; bulut bilişim uygulamaları kullanım oranı \%10,3 olmuştur. Bulut bilişim hizmeti 2016 yılında işletmelerin $\% 10,3$ '̈̈ tarafından kullanılırken, bu oran 2014 yılında \%6,8 olduğu görülmektedir. Bulut bilişim uygulamaları kullanım oranı AB-28 için aynı dönemlerde sırasıyla \%21 ve \%19 olmuştur.

Bulut bilişim uygulaması kullanımı çalışan sayısı büyüklük gruplarına göre incelendiğinde ise 2016 yılında \%20,3 ile en yüksek kullanım oranı 250 ve üzeri çalışanı olan işletmelerde görülmüştür. Aynı şekilde AB-28 genelinde de 250 ve üzeri çalışanı olan işletmeler \%45 ile en yüksek bulut bilişim uygulamaları kullanan büyüklük grubu olmuştur (TÜIKK, 2017, Sayı 15).

Yapılmış olan araştırmaların sonuçlarına göre; yıllar itibari ile bulut bilişim uygulamalarının kullanım oranında artış olduğu görülmektedir. 


\section{BULUT MUHASEBE UYGULAMALARI}

Bulut teknoloji tabanlı muhasebe uygulamalarında, Tekdüzen Hesap Planında (THP) yer alan 26 Maddi Olmayan Duran Varlıklar grubunda yer alan hesaplar kullanılabilir. Muhasebe uygulamalarında kullanılan yazılım programları, THP'de boş olan 265 YAZILIMLAR hesabına alt hesaplar açarak muhasebeleştirilebileceği gibi 267 DİĞER MADDİ DURAN VARLIKLAR hesabına alt hesap açarak da muhasebeleştirilebilir. İşletme için lisans söz konusu ise 260 HAKLAR hesabının kullanılabileceği görüşü olsa da yazılımlar ile ilgili 267 DİĞER MADDİ DURAN VARLIKLAR hesabının kullanılması daha doğru olabilir. Çünkü işletmelerde kullanılan yazılımların lisans/kullanım hakları satın alındığında bu hesap kullanılarak, 268 BİRIKMMIŞ AMORTISMANLAR (-) hesab1 ile aktifleştirilmektedir (Gelir İdaresi Başkanlığı (GiB)-THP, 01.Ağustos.2018).

Bulut muhasebe uygulamalarının muhasebeleştirilmesini muhasebe standartları açısından incelediğimizde kullanılan yazılımlar, 38 nolu Uluslararası Muhasebe Standardı (IAS 38) paralelinde olan Türkiye Muhasebe Standard 38 Maddi Olmayan Duran Varlıklar Standardına göre muhasebeleş̧irilmelidir. Bu standart; başka bir standartta özel hüküm bulunmayan maddi olmayan duran varlıklarla ilgili muhasebeleştirme yöntemlerini belirlemektedir. Maddi olmayan duran varlıklar; işletmelerin bilimsel ya da teknik bilgi, yeni süreç veya sistemlerin tasarımı ve uygulanması, lisans, fikri mülkiyet hakları, piyasa bilgisi ve markalar (marka isimleri ve yayın hakları dahil) gibi maddi olmayan kaynakların elde edilmesi, geliştirme, bakım veya iyileştirilmesi sırasında yüklenilen çeşitli borçlardır. Bu geniş kapsamlı başlıklar altındaki kalemlerin yaygın örnekleri; bilgisayar yazılımı, patentler, telif hakları, sinema filmleri, müşteri listeleri, ipotek hizmeti sunma hakları, balıkçılık lisansları, ithalat kotaları, isim hakları, müşteri ve tedarikçi ilişkileri, müşteri sadakati, pazar payı ve pazarlama haklarıdır (KGK-TMS 38, Madde 9).

Bulut teknolojiye sahip muhasebe yazılımlarının alınması durumunda, işletmelerin yapması gereken muhasebe kaydı aşağıda yer alan örnek uygulamada belirtildiği gibidir.

Örnek Uygulama: B İşletmesi, muhasebe uygulamalarında kullanılmak üzere bulut teknoloji tabanlı yazılım için $13.500+\% 18 \mathrm{KDV}$ ödeme yapmıştır. Faydalı ömrü 3 yıl ve itfa (amortisman) oranı \%33,3'dür. Ödeme kaydı ve itfa kaydı:

267 DíĞ. MADDİ OLMAYAN DURAN VARLIK. 13.50
267 01 Bulut Teknoloji Tabanlı Yazılım
191 İNDIRILECEK KDV
100 KASA
Bulut Teknoloji Tabanlı Muhasebe Yazılım Ödeme Kaydı
İtfa kaydı ise;
770 GENEL YÖNETIM GİDERLERI
268 BİRIKMIS AMORTISMANLAR
Bulut Teknoloji Tabanlı Yazılım İtfa Kaydı

2.430.15.930.-

$4.495,50$ 


\section{SONUC}

Bulut bilişimde her kullanıcı bu sisteme ulaşabileceği bir aygıtla sisteme ulaşmakta ve sistemin sunduğu hizmetlerden istediği ölçekte yararlanmaktadır. Bulut bilişim hizmet modelinde; yazılım hizmeti, platform hizmeti ve altyapı hizmeti olmak üzere üç tür hizmet modeli vardır. Genel, özel, melez ve topluluk olmak üzere kullanış biçimleri vardır. Bulut muhasebe, işletmenin bulut bilişim tabanlı muhasebe sistemini kullanarak muhasebe işlemlerini gerçekleştirmesidir.

Bulut muhasebe uygulanması işletmeler açısından incelendiğinde kullanımının yaygınlaştı̆̆ görülmektedir. Yapılan çalışmaların bu yönde olduğuna dair Türkiye'de de çalışmalar mevcuttur. Türkiye'de bulut bilişim alt yapısını kullanan muhasebe yazılımları işletmeler tarafından kullanılmaktadır. Başta bankalar olmak üzere, TESMER ile TÜRMOB gibi kurumların da bulut muhasebeyi, oluşturdukları projeler ile destekledikleri görülmektedir.

Muhasebeleştirilmesinde yazılım kullanım hakkının alınmasından dolayı Tekdüzen Hesap Planında yer alan 26 kodu ile başlayan hesapların kullanılması daha uygundur. Tekdüzen Hesap Planındaki mevcut hesaplar kullanılabileceği gibi boş olan bir hesap açılarak da muhasebe kaydı yapılabilmektedir. Muhasebe standartlarına göre de maddi olmayan duran varlıklar arasında gösterilebilir. Kiralama şeklinde ödeme söz konusu olması halinde gelecek aylara ya da gelecek yıllara ait giderler hesabını kullanarak muhasebe kaydı yapılabilmesinin mümkün olduğu yönünde görüşler de mevcuttur.

Bulut muhasebenin uygulanması teknolojik gelişmelerdeki hızla benzer oranda artmakta, işletmeler için hem olumlu hem de olumsuz etkileri söz konusudur. Olumsuz etkilerini azaltabilmek için, bilgi ve iletişim teknolojileri kullanırken güvenliği sağlamak için bilgi güvenliği geliştirilmeli, bulut muhasebe ile ilgili düzenlemelere detaylı bir şekilde yer verilmelidir. Bulut muhasebe uygulanabilmesi adına yasal düzenlemeler yapılmalıdır. Bulut bilişim altyapısının yeterli olması için alt yapı ve uluslararası şartlara uygun seviyeye zorunlu uygulamalar ile getirilmelidir.

Bilgi güvenliğinin sağlanmasında denetim yapılmalıdır. Bilişim suçları ve kişisel hakların korunması için ulusal ve uluslararası yapılan çalışmalarda, uyumlaştırma çalışmalarına öncelik verilmelidir. İşletmeler için bulut bilişim ve bulut muhasebe uygulamasında, uygulanması gereklilik arz eden bu konularda çalışmaların yapılması ile işletmeler, teknolojik gelişmenin ve hızla değişen dünyaya uyum sağlamada başarılı olabilirler. Güvenli ve riskin en aza indirgendiği muhasebe uygulamaları ile işletmelerin mali yapısının tespiti, işlemlerin güvenilir, doğruyu yansıtan raporlanması, işletme içi ve işletme dışı bilgi kullanıcılarına doğruyu yansıtacaktır.

\section{KAYNAKLAR}

Aytekin, Alper - Erdoğan, Yıldıray - Kavalcı, Kübra (2016), "Yeni Bir İş Modeli: Muhasebe Alanında Bulut Bilişim”, Uluslararası Yönetim İktisat ve İşletme Dergisi, ICAFR 16 Özel Say1s1, ss. 46-62.

Bartodziej, C. J. (2016), The Concept Industry 4.0: An Empirical Analysis of Technologies and Applications in Production Logistics, Springer Publish.

Becker, D'Arcy - Drum, Dawna (2012), "Accounting Students Will Live in the Cloud", (Workshop on Learning Technology for Education in Cloud (LTEC'12)-Lorna Uden, 
Emilio S. Corchado Rodríguez, Juan F. De Paz Santana, Fernando De la Prieta Eds.), Springer Science \& Business Media.

Bulut, Ela - Akçac1, Taner (2017), "Endüstri 4.0 ve İnovasyon Göstergeleri Kapsamında Türkiye Analizi”, ASSAM Uluslararası Hakemli Dergi, Sayı: 7, ss.50-72.

Can, Ahmet Vecdi - Kıymaz, Merve (2016), "Bilişim Teknolojilerinin Perakende Mağazacılık Sektörüne Yansımaları: Muhasebe Departmanlarında 4.0 Etkisi”, Süleyman Demirel Üniversitesi Sosyal Bilimler Enstitüsü Dergisi Y1l: 2016 Sayı: CİEP Özel Sayıs1, ss.107-117.

Cantürk, Sinem (2013), “Bulut Bilişim ve Bankacılık Sektörü”, Nisan-Haziran 2013 KPMG Gündem.

Çetin, Çağla - Yaman, Nefise - Sabah, Levent - Ayday, Erman - Ayday, Can (2013), Bulut Bilişim (Cloud Computing) Teknolojisinin Uzaktan Algılama ve Coğrafi Bilgi Sistemlerinde Uygulama Olanaklar1, Türkiye Ulusal Fotogrametri ve Uzaktan Algılama Birliği VII. Teknik Sempozyumu (TUFUAB'2013), 23-25 Mayıs 2013, KTÜ, Trabzon.

Ejder Erturan, İlkay - Ergin, Emre (2017), "Muhasebe Denetiminde Nesnelerin İnterneti: Stok Döngüsü”, Muhasebe ve Finansman Dergisi, Temmuz 2017, ss.13-30.

Elitaş, Cemal - Özdemir, Serkan (2014), "Bulut Bilişim ve Muhasebede Kullanımı", Muhasebe Bilim Dünyas1 Dergisi MÖDAV, 2014/2, ss.93-108.

Gelir İdaresi Başkanlığı (GİB), "THP-Hesap Planı Açıklamaları", http://www.gib.gov.tr/fileadmin/mevzuatek/eski/muhsisteb1ekmuh5c.htm, Erişim Tarihi: 01.Ağustos.2018.

Gilchrist, A. (2016), Industry 4.0: The Industrial Internet of Things, Apress Publish.

Henkoğlu, Türkay - Külcü, Özgür (2013), "Bilgi Erişim Platformu Olarak Bulut Bilişim: Riskler ve Hukuksal Koşullar Üzerine Bir İnceleme”, Bilgi Dünyası, 14(1), ss.62-86.

IAS 38 Intangible Assets, https://www.ifrs.org/issued-standards/list-of-standards/ias-38intangible-assets/, Erişim Tarihi: 01.Ağustos.2018.

Jamsa, Kris (2012), Cloud Computing, Jones \& Bartlett Publishers, USA.

Kelly, Jane E. - Barrow, Paul - Epstein, Lita (2016), Bookkeeping For Dummies, John Wiley \& Sons, US.

KGK, "TMS 38 Maddi Olmayan Duran Varliklar", http://www.kgk.gov.tr/Portalv2Uploads/files/DynamicContentFiles/Türkiye\%20Muha sebe\%20Standartlar1/TMSTFRS2011Seti/TMS38.pdf, Erişim Tarihi: 01.Ağustos. 2018 . 
Kuzu, Demir - Elif, Buğra - Çaka, Cansu - Tuğtekin, Ufuk - Demir, Kadir - İslamoğlu, Hakan - Kuzu, Abdullah (2016), "Üç Boyutlu Yazdırma Teknolojilerinin Eğitim Alanında Kullanımı: Türkiye'deki Uygulamalar”, Ege Eğitim Dergisi 2016 (17)2, ss.481-503.

Küçükkalay, A. Mesut (1994), "Endüstri Devrimi ve Ekonomik Sonuçlarının Analizi”, Süleyman Demirel Üniversitesi İktisadi ve İdari Bilimler Fakültesi Dergisi, S.2 (Güz), ss.51-68.

Öz, Yaşar (2016), "Bulut Bilişim (Cloud Computing) ve Muhasebe”, Bartın Üniversitesi İ.İ.B.F. Dergisi, Cilt: 7, Say1: 13, ss.63-79.

Özkurt, Cem (2016), Endüstri 4.0 Perspektifinden Türkiye'de İmalat Sanayinin Durumu: Sakarya İmalat Sanayi Üzerine Bir Anket Çalışması, Sakarya Üniversitesi FBE.

Ruparelia, Nayan B. (2016), Cloud Computing, MIT Press, London England.

Sayar, Mahmut - Yüksel, Hilmi (2018), "Endüstri 4.0 ve Türkiye Kamu Sektöründe Endüstri 4.0 Dönüşümü”, Hukuk ve İktisat Araştırmaları Dergisi, Cilt: 10, Sayı 2, ss.83-98.

Seyrek, İbrahim Halil (2011), "Bulut Bilişim: İşletmeler için Firsatlar ve Zorluklar", Gaziantep Üniversitesi Sosyal Bilimler Dergisi, 10(2), ss.701-713.

Sugahara, Satoshi - Daidj, Nabyla - Ushio, Sumitaka (2017), Value Creation in Management Accounting and Strategic Management: An Integrated Approach, John Wiley \& Sons, USA.

Türkiye İstatistik Kurumu (TÜİK), "Girişimlerde Bilişim Teknolojileri Kullanım Araştırması, 2017", http://www.tuik.gov.tr/PreHaberBultenleri.do?id=24863, (Erişim Tarihi: 01.Ağustos.2018).

Türkiye İstatistik Kurumu (TÜİK), "Girişimlerin \%45,7’si Sosyal Medya Uygulamalarını Kullandı", http://www.tuik.gov.tr/basinOdasi/haberler/2017_67_20171214.pdf, Say1: 67 / 2017, 14.Aralik.2017.

Türkiye İstatistik Kurumu (TÜİK), "Bulut Bilişim Uygulamaları Kullanım Oranı", http://www.tuik.gov.tr/basinOdasi/haberler/2017_15_20170314.pdf, Say1:15/2017, Basin Odas1 Haberleri, 14.Mart.2017.

Turan, Metin (2014), "Bulut Bilişim ve Mali Etkileri: Bulutta Vergi”, Bilgi Dünyas1, 15(2), s.296-326.

TÜSİAD, (2016), Türkiye'nin Küresel Rekabetçiliği İçin Bir Gereklilik Olarak Sanayi 4.0, TÜSİAD Yayınları.

Yıldız, Aytaç (2018), "Endüstri 4.0 ve Akıllı Fabrikalar”, Sakarya Üniversitesi Fen Bilimleri Enstitüsü Dergisi, 22 (2), ss.546-556.

Yıldız, Özcan Rıza (2009), "Bilişim Dünyasının Yeni Modeli: Bulut Bilişim (Cloud Computing) ve Denetim”, Sayıştay Dergisi, Sayı:74-75, ss.5-23. 
Y1lmaz, S. (2018), Industry 4.0 and Turkey: A Financial Perspective, (Strategic Design and Innovative Thinking in Business Operations: The Role of Business Culture and Risk Management, Hasan Dinçer vd. Ed.), Springer Publish.

Yüksel, Hakan (2012), Bulut Bilişim El Kitabı, Ocak 2012.

Yürekli, Emin - Şahiner, Abdülkadir (2017), "Muhasebe Eğitimi ve Endüstri 4.0 İlişkisi”, Akademik Sosyal Araştırmalar Dergisi, Y1l: 5, Say1: 55, Ekim 2017, ss.152-162. 